\title{
Predicting Altruism with Personality "Beyond" the Big Five
}

Sereena Dargan and Dr. Julie Aitken Schermer

Western University

\section{INTRODUCTION}

\section{Why Investigate Altruism?}

Altruistic behaviours are associated with several personal and communityrelated benefits.

$>$ Subjective well-being, self-esteem, self-efficacy, and social connection

Common Personality Models and Altruism

Traits of the Big Five and HEXACO models

$\begin{array}{ll}\text { Agreeableness } & \text { Commonly used models identify trait } \\ \text { Extraversion } & \text { (+)agreeableness, (-)neuroticism, and } \\ \text { Openness } & \text { (+)honesty-humility to be related to } \\ \text { Conscientiousness } & \text { altruistic behaviours. } \\ \text { Neuroticism } & \text { However, these models do not account } \\ \text { Honesty-Humility } & \text { for all personality traits. } \\ \text { Emotionality } & \end{array}$

Supernumerary Personality Inventory (SPI) and Altruism SPI measures personality dimensions not accounted for by the above models:

$>$ Religiosity >Conventionality

$>$ Manipulativeness $>$ Femininity

$>$ Integrity

$>$ Egotism

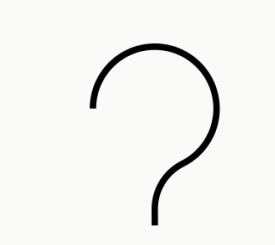

$>$ Seductiveness $>$ Humorousness

$>$ Thriftiness $\quad>$ Risk-taking

Kowalski et al. (2021) - SPI and Prosocial Behaviour Investigated associations between the SPI and two prosocial behaviours: Donation amount (DA) \& donation frequency (DF).

$>$ Found femininity and religiosity to predict DF

$>$ Found integrity and humorousness to predict DA

\section{Hypotheses}

Hypothesized femininity, integrity, and humor to positively predict altruism scores.

\section{METHOD}

\section{Participants}

256 individuals (219 females) with a mean age of 37.75 years. Recruited through snowballing.

\section{Measures}

Supernumerary Personality Inventory (SPI; Paunonen, 2002)

> Ten 15-item subscales (e.g., "My spiritual beliefs help me through stressful times")

Subscale reliabilities range from $\alpha=.66$ to .95

Self-Report Altruism Scale (SRAS; Rushton et al., 1981)

$>$ One 20-item subscale ( $\alpha=.87$ ) (e.g., "I have donated goods or clothes to a charity") Compassionate Altruism Scale (CAS; O'Connor et al., 2015)

> Three 15-items subscales (e.g., "I paid for lunch when they were broke")

$>$ Subscales: Family $(\alpha=.97)$, friends $(\alpha=.97)$, strangers $(\alpha=.98)$

Procedure

Participants completed demographic questions, the SPI, SRAS, and CAS as an online survey.

\section{RESULTS}

Significant inter-scale correlations were found between the SRAS and CAS.

$>$ Correlations ranging from $r=.304$ to .753

SPI dimensions and age accounted for $10-20 \%$ of the variance in altruism scores.

\section{Self-Report Altruism Scale scores predicted by:}

$>$ Age $(\beta=.309, p<.001)$

$>$ Integrity $(B=.338, p<.01)$

Risk-taking $(\beta=.320, p<.01)$

Compassionate Altruism Scale - Family scores predicted by:

$>$ Humorousness $(B=.229, p<.01)$

Compassionate Altruism Scale - Friends scores predicted by:

$>$ Age $(ß=-.225, p<.01)$

Compassionate Altruism Scale - Strangers scores predicted by:

$>$ Femininity $(B=-.297, p<.001)$

$>$ Religiosity $(\beta=.291, p<.01)$

\section{DISCUSSION}

Age positively predicting SRAS scores is consistent with theories of development and motivation.

$>$ Age improves perspective-taking and lessens egocentrism. Integrity predicting SRAS scores could reflect the trait's conceptual similarity to moral identity and associated prosocial behaviours. Results for risk-taking were not hypothesized but may reflect the degree of risk involved in decision to selflessly expend personal resources.

Humorousness predicting CAS-family scores is consistent with the evolutionary perspective of humor.

Age negatively predicting CAS-friends demonstrates importance of context in predicting altruism.

Suggests that altruism towards friend groups is highest when these groups are most salient (i.e., younger vs. older adulthood) Findings for femininity contradict past studies but might reflect perceived levels of physical risk - especially in cases involving strangers.

Religiosity predicting CAS-stranger scores is consistent with the prosocial inclinations found within most religious subcultures - particularly towards strangers.

Limitations and Future Directions

Uneven gender distribution, recruitment technique, self-report nature of altruism. Incorporation of other measures of personality to better establish the predictive ability of the SPI.

\section{Conclusions}

Results provide new evidence for the roles of SPI traits in predicting altruism as well as a foundation for future research to explore the dynamics of personality and altruistic behaviour across situations. Kowalski, C.M., Simpson, B., \& Schermer, J.A. (2021). Predicting donation behaviour with the Super
Personality Inventory. Personality and Individual Differences, 168(August 2020), 110319. Paunonen, S.V. (2002). Design and construction of the Supernumerary Personality Inventory. The University of Western Ontario Psychology Research Bulletin, 763.

Paunonen, S.V., \& Jackson, D.N. (2000). What lies beyond the Big Five? Plenty! Journal of Personality, (68)5, 821$835 \mathrm{http}: / /$ doi.org/10.1111/1467-6494.00117 